\title{
High Functioning Autism Spectrum Disorders in Adults: Consequences for Primary Caregivers Compared to Schizophrenia and Depression
}

\author{
Inge A. C. Grootscholten ${ }^{1,3}$ [D $\cdot$ Bob van Wijngaarden ${ }^{2} \cdot$ Cornelis C. Kan $^{1}$
}

Published online: 8 January 2018

(c) The Author(s) 2018. This article is an open access publication

\begin{abstract}
Primary caregivers experience consequences from being in close contact to a person with autism spectrum disorder (ASD). This study used the Involvement Evaluation Questionnaire to explore the level of consequences of 104 caregivers involved with adults with High Functioning ASD (HF-ASD) and compared these with the consequences reported by caregivers of patients suffering from depression and schizophrenia. Caregivers involved with adults with an HF-ASD experience overall consequences comparable to those involved with patients with depression or schizophrenia. Worrying was the most reported consequence. More tension was experienced by the caregivers of ASD patients, especially by spouses. More care and attention for spouses of adults with an HF-ASD appears to be needed.
\end{abstract}

Keywords Autism spectrum disorders $\cdot$ High functioning $\cdot$ Caregiver consequences $\cdot$ Parents $\cdot$ Spouses

\section{Introduction}

It has been recognized since the 1950 s that a psychiatric disorder can have a major impact on the significant others (SO: parents, spouses, siblings, friends) of the patient (e.g. Schene 1990; Baronet 1999; Cuijpers and Stam 2000; Wittmund et al. 2002; Ostman et al. 2005; Gelkopf and Roe 2014). Most studies in the area of family caregiving have been conducted on SO concerned with patients with physical (e.g. Geurtsen et al. 2010) or mental disabilities (e.g. Murphy et al. 2007), dementia (e.g. Barusch and Spaid 1989) or psychiatric disorders such as schizophrenia or affective

Dr. B. van Wijngaarden is retired from the Netherlands Institute of Mental Health and Addiction, Utrecht, the Netherlands.

Grootscholten currently works as a psychiatrist at Max Ernst GGZ in Arnhem, the Netherlands.

Inge A. C. Grootscholten

Inge.Grootscholten@max-ernst.nl

1 Department of Psychiatry, Radboud University Medical Center, Nijmegen, Reinier Postlaan 4, 6525 EX Nijmegen, The Netherlands

2 Netherlands Institute of Mental Health and Addiction, Da Costakade 45, 3521 VS Utrecht, The Netherlands

3 Arnhem, The Netherlands disorders (e.g. Goossens et al. 2008; van Wijngaarden et al. 2009; Granek et al. 2016; Kumar et al. 2015).

Autism spectrum disorders (ASD) are developmental disorders characterized by an impairment of reciprocal communication and social interactions and the presence of restricted stereotypical behaviors and interests (American Psychiatric Association 2013).

What is known about the impact of ASD on their SOs? Literature published on the impact of ASD on primary caregivers mainly focuses on the consequences for parents (mostly mothers) with an autistic child that often has a concomitant intellectual disability as well as a language disorder (e.g. Milgram and Atzil 1988; Hartley et al. 2011; Hayes and Watson 2013; Burke and Heller 2016; Tomeny 2016). These parents experience a profound number of consequences such as high levels of parenting stress (Lecavalier et al. 2006; Milgram and Atzil 1988) or feelings of guilt and failure (van Tongerloo et al. 2015). These levels of consequences are high compared to parents of children with a normal development, but also high compared to parents with a child with another disability such as Down syndrome, cerebral palsy, fragile X or Fetal Alcohol Spectrum Disorder (Hayes and Watson 2013). As a result of these chronic high levels of parenting stress these parents report an increase of mental health problems such as the risk of developing a depressive disorder (e.g. Tomeny 2016; Lin 2011; Lecavalier et al. 
2006; Orsmond et al. 2007). See Tint and Weiss (2016) or

Karst and Van Hecke (2012) for a recent review.

In the 1970s and 1980s it was thought that $>75 \%$ of ASD patients has an intellectual disability (Schalock et al. 2007). In more recent years, partly due to the changed perspective on autism as a spectrum disorder, more attention has been paid to those with ASD without an intellectual disability, called High Functioning ASD (HF-ASD). They have an average to above average intelligence (IQ> 70) and are often considered as having a 'milder type' of ASD (Baron-Cohen 2000).

Rao and Beidel (2009) have studied the impact on parents of children with HF-ASD, and concluded that in case of HF-ASD the levels of parenting stress, the restriction of family functioning, and the risk of psychological problems and poorer mental and physical health are higher compared to families with children without a psychiatric disorder. The higher intellectual functioning of the children did not ameliorate the high levels of stress in their parents. They also described that children with HF-ASD had less externalizing (behavioral) problems, but higher levels of internalizing problems, such as depression and anxiety, which would also contribute to the parental stress.

HF-ASD patients can often go unrecognized until well into adolescence or adulthood, possibly because they are able (at least to some extent) to compensate for social clumsiness by copying the behavior of their peers and because they are protected by structure and support from SO. But when changing circumstances (such as going to college, finding a job or becoming intimately involved) demand skills which exceed their abilities, they become aware of their inadequate coping and their deficits in social interaction (Marriage et al. 2009; Lehnhardt et al. 2013).

\section{What Do We Know About Adults with HF-ASD and the Impact on Their SO?}

When focusing on adults with ASD, most literature is concerned with the problems of transition of the autistic child to adolescence and adulthood, difficulties with the different healthcare services organized for children and adults, and how this impacts the parents who continue to parent longer than parents with children without ASD (e.g. Cadman et al. 2012; Smith et al. 2012; Weiss et al. 2016; Hartley and Schultz 2015; Burke and Heller 2016), but these adults often had intellectual disabilities as well. Cadman et al. (2012) concluded that adolescence and young adulthood are associated with high levels of caregiver burden, that this burden was greater in ASD compared to attention-deficit/hyperactivity disorder and that this was mainly explained by the patient's unmet needs.

Renty and Roeyers (2007) studied the marital satisfaction of 21 couples consisting of a HF-ASD male and a non-ASD female. They found that women whose husband showed less autism-specific traits reported higher levels of marital satisfaction. They also found that the marital adaptation in the men was significantly associated with more received and perceived social support from the spouse and from family and friends. Lau and Peterson (2011) studied the attachment styles of 22 adults with HF-ASD (7 males, 15 females) and found that $73 \%$ of them had an avoidant style of attachment, as opposed to the secured romantic attachment style found in $72 \%$ nonASD spouses. Spouses of HF-ASD showed less marital satisfaction, but this could be explained by the presence of an ASD-child. They concluded that the husband's or wife's ASD status had little impact upon any aspect of marital quality.

In our clinical practice with adult patients newly diagnosed with HF-ASD we encounter primary caregivers who report a significant impact on their daily lives, relationships and family life. In order to assess the magnitude of this impact on the SO, we have acquired self-report data on the level of consequences and general aspects of their health in a sample of SO of adult HF-ASD patients, and have compared these data to data of samples of SO of patients with depression or schizophrenia. The reason we have compared our data to these two groups is because schizophrenia and major depressive disorders are both, although different in nature, considered as serious psychiatric disorders. HF-ASD is considered by some as a milder form of ASD, so it would be interesting to compare the consequences of HF-ASD for SO to these serious disorders.

For this study we hypothesized the following:

(1) The impact on SO of adults with HF-ASD is comparable to the impact on SO of patients with depression or schizophrenia

(2) More symptoms of ASD recognized by the SO correlate with a higher level of consequences reported by the SO

(3) The impact on parents or spouses will be different

(4) As in the case of schizophrenia and depression, SO who experience consequences of the disorder of their child/ partner/family member will be at risk of developing (mental) health problems themselves

\section{Method}

\section{Inclusion Criteria and Patient Samples}

Data on the consequences of depression or schizophrenia on caregivers originate from the research done by van Wijngaarden et al. (2009). The depression sample consisted of relatives, friends, partners or other caregivers of patients who suffered from depression (major depressive disorder, dysthymic disorder, other depressive disorders). The patients were all treated in a mental hospital specialized in 
the treatment of depression in the Netherlands. Patients were asked for written permission to contact a SO and to send them a questionnaire by mail. From this data we used the outpatient data only ( $\mathrm{N}=237)$, to match our population.

The schizophrenia sample originated from the European EPSILON study (Becker et al. 2000), which identified a representative cohort of patients with schizophrenia. From this sample we used the outpatient data from the Northern European countries: the Netherlands, Denmark and the United Kingdom $(\mathrm{N}=150)$. For more details see van Wijngaarden et al. (2009).

The ASD data were collected at the outpatient clinic of the Radboud University Medical Center in Nijmegen, the Netherlands. This clinic has a special outpatient program for adults suffering from developmental disorders (ASD and/ or $\mathrm{AD}(\mathrm{H}) \mathrm{D})$.

Adults referred to this department experience, for example, problems with social interaction, non-verbal communication, and/or restricted patterns of behavior and interests. These may cause problems in intimate and professional relationships, often resulting in social isolation, conflicts at work or within the family unit. The majority of these adults has not been diagnosed with an ASD during childhood due to their compensating normal to high intelligence (IQ> 70).

Patients who have been diagnosed with ASD were offered to participate in a psycho-educational group course. In this course information about ASD was given, and the impact of different aspects of ASD on an individual's life was explored.

Every participant of the psycho-educational course had to bring a SO. This SO could be a spouse, a parent, a sibling, a friend, or a professional caregiver. At the Radboud Medical Center it is considered important that the information given in the psycho-educational course does not only reach the patient, but his/her surroundings as well. Someone who is close to the patient can be extremely helpful to the patient in recognizing the specifics of ASD in his/her own life, and can contribute to the generalization of the knowledge about ASD to everyday life beyond the group meetings.

Reasons for exclusion from the psycho-educational course were: intellectual disability (IQ $<70)$, concurrent psychosis, or a personality disorder of such an extent that it would interfere strongly with participation in a group with other patients. Patients who were excluded received individual psycho-education.

SO of ASD patients were asked to complete a number of questionnaires, including the Involvement Evaluation Questionnaire (IEQ), General Health Questionnaire (GHQ-12), and Autism-Spectrum Quotient (AQ), before the start of the psycho-educational course. Informed consent was signed by all the participants for use of data for research.

The Medical Ethics Committee of the Radboud University Medical Centre stated that no ethical approval was needed because of the non-invasive character of the selfreport questionnaires.

\section{Measures}

The IEQ is an internationally validated self-rating questionnaire which measures consequences experienced by those involved with people with psychiatric illnesses (van Wijngaarden et al. 2000, 2004, 2009; Martin et al. 2015; Cuijpers and Stam 2000). The IEQ-scores correlate to patients' characteristics, and predict caregiver distress as assessed with the GHQ-12 (Goossens et al. 2008; Goncalves-Pereira et al. 2013). IEQ-scores assess various aspects of caregiving consequences such as the encouragement, supervision and care the caregiver has to provide to the patient, strain experienced on the relationship due to interpersonal problems between patient and caregiver, and to the caregiver's worries. The core module measuring the 'caregiving consequences' comprises 31 items, which focus on the objective aspects of the caregiver's experience, scored on 5-point Likert scales $(0=$ never, $1=$ sometimes, $2=$ regularly, $3=$ often and $4=$ always). The questionnaire is divided into four subscales: Tension, referring to a potentially strained interpersonal atmosphere between the patient and the SO; Supervision, which, amongst others, refers to the SO's task of keeping the patient from committing dangerous acts, or the supervision of taking medication; Worrying refers to worrying about the patient's health, safety and future, and Urging refers to the motivation and activation of the patient. The time-frame is the 4 weeks prior to the assessment. The IEQ has shown extensive reliability and internal consistency, in the Netherlands as well as internationally (Schene 1990; Becker et al. 1999, 2000; van Wijngaarden et al. 2000; Magne-Ingvar and Ojehagen 2005; Goossens et al. 2008; Geurtsen et al. 2010). It can be administered to any caregiver, including friends and neighbors, who are in contact with the patient for at least $1 \mathrm{~h} /$ week.

The $G H Q-12$ is a well-validated self-administered instrument for the detection and measurement of psychopathology in the community (Goldberg et al. 1997; Goldberg and Williams 1988). It consists of 12 questions referring to subjects such as lack of sleep, loss of confidence, and feeling depressed. It is used to identify general emotional distress and possible health risks for the caregiver. Higher GHQ scores represent higher levels of distress. Possible answers are: 'better than usual', 'as good as usual', 'worse than usual', and 'much worse than usual' for positively phrased questions, and 'not at all', 'same as usual', 'rather more than usual', and 'much more than usual' for the negatively phrased questions.

The $A Q$ was used to capture the severity of ASD symptoms. The AQ was developed by Baron-Cohen et al. (BaronCohen et al. 2001) and measures the amount of autistic traits 
in adults of normal intelligence. It has been broadly tested and widely used to differ between ASD and non-ASD caseness in the process of patient evaluation. The 50 item selfreport questionnaire includes five domains: Social skill, Attention switching, Attention to detail, Communication, and Imagination. We used the 'parent report version'; this can be completed by a parent or other primary caregivers (Baron-Cohen et al. 2006).

The Dutch AQ has shown good sensitivity and specificity (Hoekstra et al. 2008).

\section{Data Analysis}

\section{IEQ}

In order to study the differences in IEQ subscale scores between the depression, schizophrenia and ASD samples, so-called 'consequences indices' (C-indices) were computed, as described by van Wijngaarden et al. (2009). IEQ item scores of ' 0 ' or ' 1 ' (never, sometimes) are considered as indicating 'no real consequence'. Item scores of ' 2 ' or higher (regularly, often or always) are considered as indicating a 'real consequence'. The number of 'real consequences' are computed and divided by the total number of items in the scale. Four subscale $\mathrm{C}$-indices and one overall $\mathrm{C}$-index (total score), all ranging from ' 0 ' (no consequences at all) to ' 1 ' (maximum level of consequences) were computed this way.

\section{GHQ-12}

There are three different ways of scoring the GHQ-12: the binary $(0,0,1,1)$, chronic $(0,1,1,1)$ and Likert scoring $(0,1,2,3)$ (Goldberg et al. 1997). The Likert scoring gives a wider and steadier score distribution to assess severity and can be used for correlation analysis. The Likert scoring was therefore used in this study. The possible score ranges from 0 to 36, with higher scores representing higher levels of distress. Threshold for caseness varies in different populations studied (Goldberg et al. 1998). As no threshold was published for the Dutch population, the threshold for the German population as published by Schmitz et al. (1999) was used (11/12). We expected Germany, being a neighboring country of the Netherlands with approximately the same socio-economic situation and organization of health care, to be the best comparable country available.

\section{AQ}

There are two ways of scoring the AQ: a 4-point Likert score or a binary one in which answers 'definitely agree' and 'agree' score as 1 on autism positive traits and 'definitely disagree' and 'disagree' score as 1 on autism negative traits. The binary score is proposed by Baron-Cohen and is used in this research. It has a minimum of 0 and a maximum score of 50, the higher indicating more autistic traits. The cut-off for caseness was 32 as proposed by Baron-Cohen et al. (2001).

\section{Statistics}

The statistical calculations were made using the IBM Statistical Package for the Social Sciences version 22.0. Comparisons between IEQ C-indices scores for the different disorders and SO-groups were made by the Kruskal-Wallis test for non-parametrically distributed, independent samples as advised by Field (2013). Comparison between GHQ scores were made by the Mann-Whitney test. All effects are reported at a significance level of $p<.05$, unless stated differently. Effect sizes were computed using Pearsons' r. Correlation of IEQ with GHQ scores and of IEQ with AQ scores were calculated using the Spearman rank correlation coefficient (two-tailed) for non-parametrically distributed variables. Two-tailed ANOVA was used to compare AQ data in the SO-groups. We did not control for any demographic factors throughout the analysis.

\section{Results}

Between 2006 and 2009 approximately 660 patients were referred to the outpatient clinic for diagnostic assessment of ASD. $38.5 \%$ of these 660 patients was not diagnosed with an ASD, 17\% was classified with autistic disorder, $19 \%$ with Asperger's disorder, and 21\% with PDD-NOS by use of Diagnostic and Statistical Manual of Mental Disorders (DSM-IV TR) (American Psychiatric Association 1994). $1.5 \%$ of the referred patients did not finish the course of examination. No files were found in the archives with respect to $3 \%$ of the patients.

129 of the 376 patients diagnosed with ASD enrolled in the psycho-educational group course. There were several reasons, apart from not meeting the inclusion criteria, for patients not to participate in the psycho-educational group, ranging from unwillingness to participate in a group or living too far away from the center, to having the opinion that a psycho-educational group could do nothing to alleviate his/her problems. Bi-nominal regression analysis showed that there was no selection bias, based on subclassification according to DSM-IV, and age or gender of the patient.

Of the $129 \mathrm{SO}$ who joined a patient in the psycho-educational group course between 2006 and 2009, 110 handed in the questionnaires. Due to missing data, questionnaires of $104 \mathrm{SO}$ could be used for analysis. 


\section{Subject Characteristics}

Table 1 shows socio-demographic characteristics of patients and SO for ASD, compared to schizophrenia and depression. SO who were not a parent or a spouse (e.g. a sibling, friend, child, neighbor, colleague, or coach) are combined in the group named 'other' because of the low number of SO in each of these remaining groups, and the comparable level of consequences experienced by these SO.

There were several substantial differences between the three groups concerning the age and gender of patients and SO. The depression sample consisted mostly of spouses who lived in the same household and were of approximately the same age as the patients. Of the three samples they spent the most time together. The schizophrenia sample consisted mostly of mothers who were the main caregivers of their schizophrenic sons. The ASD sample consisted mostly of spouses, but there was a gender difference in comparison to the depression sample: most of the patients in the ASD sample were males, and most of the SO were females, while in the depression sample the gender distribution was almost 50-50. These differences in gender distribution can be explained by the specific gender distribution of the disorder: ASD is diagnosed at least three times as often in males as in females (Muhle et al. 2004; Loomes et al. 2017).

\section{IEQ Scores}

Our sample was too small to perform a reliable confirmatory factor analysis. In order to get some idea of the validity of the IEQ for an ASD sample, a preliminary exploratory factor analysis was conducted. It showed a slightly different factor structure compared to the standard IEQ structure. We found four subscales, which consisted of Tension, Worrying, Urging and Supervision combined together, and a fourth mixed scale. Tension showed to be the most robust factor. Five items referring to Supervision and Urging were not included in one of the factors.

In order to test the reliability of the IEQ in the ASD-population, Crohnbach's alpha was computed, using the standard IEQ scales. These were acceptable for the total score (0.8), the subscale Tension (0.8), subscale Worrying (0.7) and subscale Urging (0.7). Subscale Supervision, however, had an alpha of 0.3. Because this subscale is not reliable in our sample it was not used in the comparison analysis.

Table 1 Socio-demographic characteristics of patients and caregivers by diagnostic group

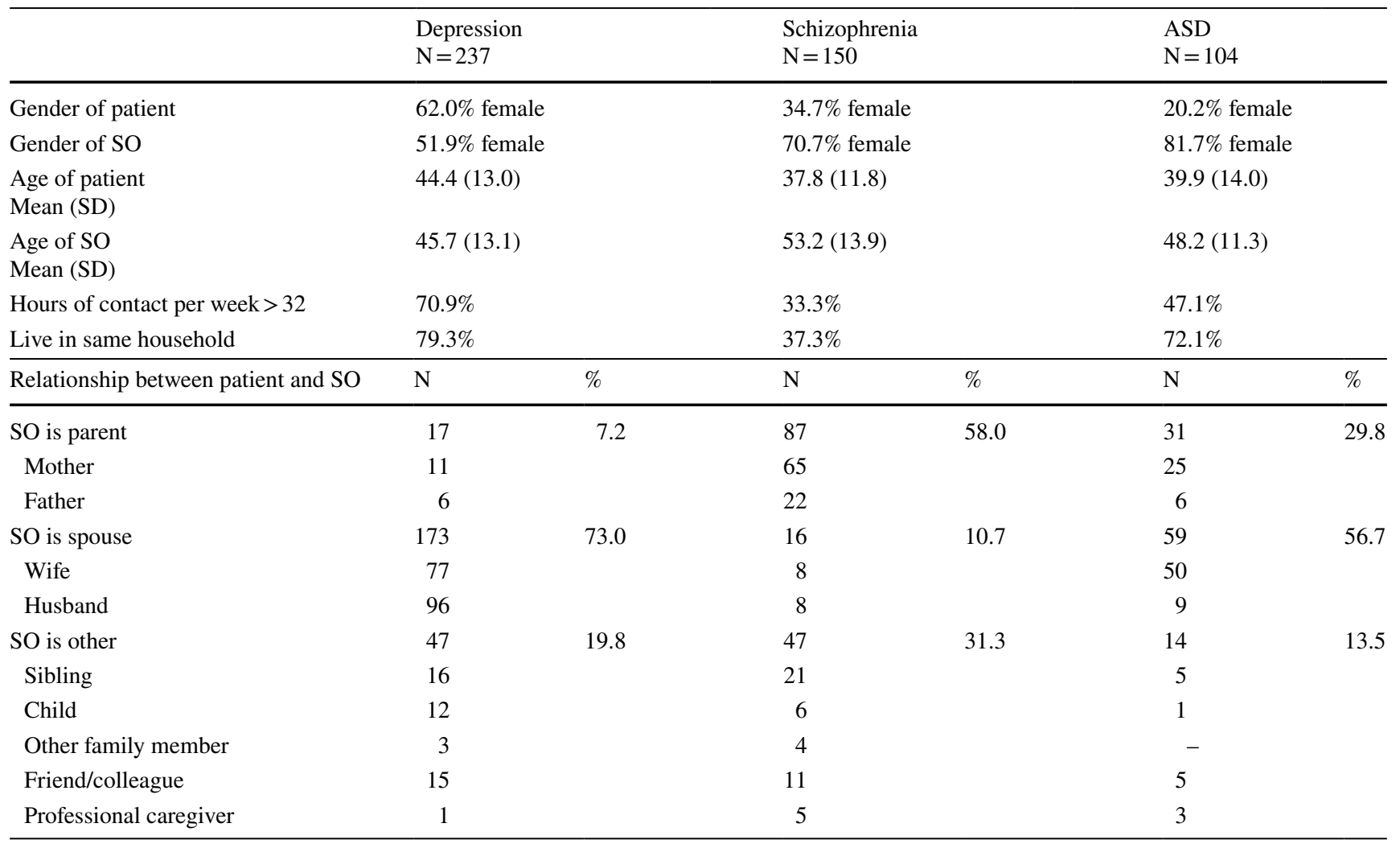

Part of this data was used in van Wijngaarden et al. (2009)

$A S D$ Autism spectrum disorder, $S O$ significant other 
Caregiver consequences in the depression, schizophrenia and ASD sample were compared using the total score and the subscales Tension, Worrying, and Urging. In Table 2 the mean C-indices of the IEQ scales for the three samples are presented. No difference was found for the total consequences. On the subscale of Tension, however, there was a significant difference between the three samples $[\mathrm{H}(2)=19.76 \mathrm{p}<.000]$. Pair-wise comparison showed that Tension was reported significantly more often by the $\mathrm{SO}$ of ASD, compared to the schizophrenia (effect size $r=0.28$ ) and depression sample $(\mathrm{r}=0.17)$.

\section{GHQ-12 Scores}

A score above threshold (11) indicates psychiatric morbidity or severe emotional distress. The mean score on the GHQ-12 was 12.56 for the SO in the schizophrenia sample, and 14.56 for the SO in the ASD sample, which where both clearly above the threshold (Table 3 ). In fact, $49 \%$ of the SO of schizophrenia and $62 \%$ of SO of ASD patients scored above the threshold of 11 and were therefore at risk of developing health problems themselves. The differences between the SO in both samples were significant. SO of ASD patients experienced significantly more emotional distress compared to SO of schizophrenic patients $[\mathrm{U}=9130.00, \mathrm{p}=.006, \mathrm{r}=0.18]$. Also, there was a significant positive correlation between the IEQ (subscales and overall-score) and the GHQ-12 scores, meaning that higher levels of consequences are correlated with more distress. No GHQ-12 data were available for the depression sample.

\section{Looking Closer at Caregivers Confronted with ASD:}

\section{IEQ}

In Table 4 the mean C-indices of the IEQ scales for the different groups of SO connected to a patient with ASD are presented. Significant differences between the groups of primary caregivers were found on all three subscales and on the total consequences score. Differences were greatest on subscale Tension $[\mathrm{H}(2)=20.98 \mathrm{p}<.000]$. Pairwise comparison showed that spouses scored significantly higher than both parents $(\mathrm{p} \operatorname{adj}=.008 \mathrm{r}=0.31)$ and others $(\mathrm{p} \operatorname{adj}<.000$ $r=0.48)$.
Table 2 Mean C-index IEQ-scores for caregivers by diagnostic group

\begin{tabular}{lllll}
\hline IEQ subscales & Depression & Schizophrenia & ASD & p* \\
& $\mathrm{N}=237$ & $\mathrm{~N}=150$ & $\mathrm{~N}=104$ & \\
& Mean C-index (SD) & Mean C-index (SD) & Mean C-index (SD) & \\
\hline Tension & $0.16(0.21)$ & $0.12(0.17)$ & $0.24(0.23)$ & $<.000$ \\
Worrying & $0.31(0.31)$ & $0.36(0.31)$ & $0.34(0.26)$ & .162 (n.s.)\# \\
Urging & $0.15(0.19)$ & $0.21(0.26)$ & $0.17(0.19)$ & .079 (n.s.) \\
Total score & $0.17(0.16)$ & $0.18(0.17)$ & $0.19(0.14)$ & .076 (n.s.) \\
\hline
\end{tabular}

Part of this data was used in van Wijngaarden et al. (2009)

$A S D$ Autism Spectrum Disorder, IEQ Involvement Evaluation Questionnaire

*Kruskal Wallis for independent samples

${ }^{\#}$ n.s.: non-significant p > 05

Table 3 Correlation between GHQ-12 and IEQ for caregivers of schizophrenia and ASD

\begin{tabular}{lll}
\hline & GHQ-12 schizophrenia & GHQ-12 ASD \\
\hline Mean score (SD) & $12.56(6.36)$ & $14.56(6.23)$ \\
GHQ-12 score $>11$ & $48.6 \%$ & $61.8 \%$ \\
\hline IEQ subscales & Correlation coefficient & Correlation coefficient \\
\hline Tension & $.430^{* *}$ & $.533 * *$ \\
Worrying & $.347^{* *}$ & $.402 * *$ \\
Urging & $.272^{* *}$ & $.317 * *$ \\
Total score & $.407 * *$ & $.531^{* *}$ \\
\hline
\end{tabular}

$A S D$ Autism Spectrum Disorder, GHQ General Health Questionnaire, IEQ Involvement Evaluation Questionnaire

*Mann Whitney U

**p (2-tailed) <.001 p value and correlation coefficient were calculated using Spearman's rho 
Table 4 Mean C-index IEQ-scores and GHQ-12 scores for parents, spouses and other caregivers in ASD

\begin{tabular}{lllll}
\hline IEQ subscales & ASD & ASD & ASD & p* \\
& Parent & Spouse & Other & \\
& Mean (SD) & Mean (SD) & Mean (SD) & \\
& $\mathrm{N}=31$ & $\mathrm{~N}=59$ & $\mathrm{~N}=14$ & \\
\hline Tension & $0.16(0.17)$ & $0.32(0.24)$ & $0.06(0.15)$ & $<.000$ \\
Worrying & $0.44(0.25)$ & $0.32(0.24)$ & $0.21(0.30)$ & .011 \\
Urging & $0.22(0.18)$ & $0.16(0.19)$ & $0.09(0.16)$ & .024 \\
Total score & $0.20(0.13)$ & $0.21(0.14)$ & $0.10(0.13)$ & .018 \\
GHQ-12 & $13.87(4.87)$ & $15.91(6.68)$ & $10.15(4.93)$ & .002 \\
\hline
\end{tabular}

$A S D$ Autism Spectrum Disorder, $G H Q$ General Health Questionnaire, $I E Q$ Involvement Evaluation Questionnaire

*p Value was calculated using Kruskal-Wallis for independent samples

Parents scored higher on subscale Worrying compared to other caregivers ( $\mathrm{p}$ adj $=.012 \mathrm{r}=0.43$ ), but the difference between parents and spouses was non-significant.

Parents scored higher on subscale Urging compared to other caregivers $(\mathrm{p}$ adj $=.025 \mathrm{r}=0.39$ ), but in this case also, differences between parents and spouses were non-significant.

Both parents and spouses scored higher on total consequences score than other caregivers (parents vs. others $\mathrm{p}$ adj $=.039, \mathrm{r}=0.37$, spouses vs. others $\mathrm{p}$ adj $=.017$ $r=0.32$ ). Also in this case, parents and spouses did not differ.

\section{GHQ-12}

Table 4 shows that parents and spouses have higher GHQ12 scores compared to other caregivers (parents vs. others $\mathrm{p} \operatorname{adj}=.05, \mathrm{r}=0.36$, spouses vs. others $\mathrm{p}$ adj $=.001$ $r=0.40$ ), but the difference between parents and spouses was non-significant.

\section{AQ Scores}

The mean score on the AQ was $34(\mathrm{SD}=7)$, well above the cut-off for caseness of 32 points (Table 5).

Cronbach's alpha for the subscales was medium to acceptable: Social skill: 0.7, Attention switching: 0.6, Attention to detail: 0.7, Communication: 0.6, Imagination: 0.6. The Kruskal-Wallis test showed no significant difference in the AQ score between the different SO groups. There was no significant correlation between the total amount of autistic traits recognized by the SO and the consequences assessed with the IEQ (Table 6).

\section{Discussion}

The aim of this study was to investigate the consequences experienced by SO of adult HF-ASD patients and to compare these with the consequences experienced by $\mathrm{SO}$ of patients with depression or schizophrenia. The main outcome of this study is that the overall consequences experienced by the SO of adult HF-ASD patients are comparable to
Table 5 Mean AQ-scores scores for parents, spouses and other caregivers in ASD
Table 6 Correlation between total AQ score and mean C-index IEQ-scores

\begin{tabular}{llllll}
\hline & $\begin{array}{l}\text { Total } \\
\mathrm{N}=104\end{array}$ & $\begin{array}{l}\text { Parent } \\
\mathrm{N}=31\end{array}$ & $\begin{array}{l}\text { Spouse } \\
\mathrm{N}=59\end{array}$ & $\begin{array}{l}\text { Other } \\
\mathrm{N}=14\end{array}$ & $\mathrm{p}^{*}$ \\
\hline Total score AQ & $34.03(7.03)$ & $33.25(6.72)$ & $34.24(7.67)$ & $34.95(4.11)$ & $.904($ n.s.) \\
Social skill & $7.80(1.98)$ & $7.61(2.35)$ & $7.89(1.83)$ & $7.82(1.74)$ & $.907($ n.s. $)$ \\
Attention switching & $7.87(1.83)$ & $7.70(1.78)$ & $7.80(1.95)$ & $8.58(1.16)$ & $.707($ n.s $)$ \\
Attention to detail & $5.24(2.45)$ & $5.36(2.18)$ & $4.95(2.62)$ & $6.42(1.98)$ & $.612($ n.s. $)$ \\
Communication & $6.63(2.09)$ & $6.54(2.11)$ & $6.75(2.08)$ & $6.25(2.22)$ & $.846($ n.s. $)$ \\
Imagination & $6.50(2.15)$ & $6.04(2.26)$ & $6.85(2.08)$ & $5.88(2.02)$ & .253 (n.s.) \\
\hline
\end{tabular}

$A S D$ Autism Spectrum Disorder, $A Q$ Autism-spectrum Quotient

*Kruskal-Wallis test for non-parametric data

${ }^{\#}$ n.s.: non significant $\mathrm{p}>.05$

\begin{tabular}{llllll}
\hline & & C-index tension & $\begin{array}{l}\text { C-index } \\
\text { worrying }\end{array}$ & C-index urging & $\begin{array}{l}\text { C-index } \\
\text { total } \\
\text { score }\end{array}$ \\
\hline Total score AQ & Spearman's rho & .042 & .140 & -.070 & .048 \\
& $\mathrm{p}$ (2-tailed) & .716 & .221 & .543 & .676 \\
\hline
\end{tabular}

$A Q$ Autism-spectrum Quotient, IEQ Involvement Evaluation Questionnaire 
those of patients with depression or schizophrenia. On Tension they even score significantly higher than $\mathrm{SO}$ in the other two samples. This is an important result, because HF-ASD in adults is often not recognized or diagnosed, and support and treatment for ASD patients and their SO have never been a major focus of attention in mental health. Also, HF-ASD is sometimes regarded as a milder form of ASD (BaronCohen 2000). Nonetheless, the consequences, especially for relationships, can be substantial. This is consistent with our findings in the GHQ-12 data, which show that primary caregivers of HF-ASD patients experience profound emotional distress, and are beyond average at risk of developing mental health problems themselves. These patients and their SO have been feeling isolated, neglected and poorly understood, and have therefore not been receiving the support they needed.

We found that parents and spouses experience significantly more consequences than other ASD caregivers. This can be explained by the more intense and emotional bonding between a spouse or parent and the patient, the large amount of time they spend together in a household, and the different expectations that the caregiver has of their spouse or child, compared to a more distant relationship. Other researchers also found that the amount of time spent together/living together with the patient is an important predicting factor on experienced consequences (van Wijngaarden et al. 2009; Ostman et al. 2005; Martin et al. 2015; Kronenberg et al. 2016).

\section{Specifics of ASD as Hypothetic Explanations for the Consequences Found}

Because of the high levels of heritability of autistic traits (Muhle et al. 2004; Hoekstra et al. 2007), SO of ASD patients have a higher risk of having another family member affected by ASD than the general population (van Steijn et al. 2012). This is recognized as an additional cause of stress in mothers with multiple children with ASD (Orsmond et al. 2007; Ekas et al. 2009). This may also be the case for spouses who, besides having a partner with ASD, have one or more children with ASD or another disability (van Steijn et al. 2014; Lau and Peterson 2011).

Parents of adults with HF-ASD reported high levels of worrying. It is known from research concerning parents of young children that parenting a child with ASD can cause high levels of parenting stress and is correlated with depression in mothers, but it was believed that this stress diminished as the child grew older (Lounds et al. 2007; Ekas and Whitman 2010; Hartley et al. 2011). Our findings show that parents continue to worry profoundly about their children with ASD, even when they have reached adulthood. This is consistent with the research by Cadman et al. (2012) who found that caregivers of adolescents and young adults with
ASD had very high levels of burden, a level that was comparable to caregivers of persons with an acquired brain injury.

Spouses of HF-ASD patients experience more tension in their relationship with the patient compared to parents. When a partner becomes a patient, more role-taking confusion occurs than when the patient is a child. Spouses sometimes talk about their mentally ill partner in terms of "having another child" (Wittmund et al. 2002). This is confirmed by Ostman et al. (2005) and Cuijpers and Stam (2000) who also found that spouses showed increased burden compared to parents and others.

Based on our clinical experience, the lack of mutual reciprocal interaction, one of the main disabilities in patients with HF-ASD, is probably a major additional factor contributing to the perceived burden of the spouses. Due to the ability to 'feel' and understand the other person's feelings and needs, and responding accordingly, reciprocal interaction is valued by many as essential for a fulfilling intimate relationship. This requires a certain amount of 'theory of mind', often lacking in patients with ASD (Baron-Cohen 1991).

We believe parents are less burdened by this, because of the difference in expectations that a parent has of a child compared to the expectations one has of a spouse or partner (van Tongerloo et al. 2015).

Another explanation for the higher levels of tension reported by spouses of HF-ASD patients is that of gender: Wittmund et al. (2002) found that female spouses of psychiatric patients were at a higher risk of getting depressed themselves than male spouses. In the ASD-sample, $85 \%$ of the spouses was female (50 women vs. 9 men), which reflects the gender distribution of ASD (Loomes et al. 2017). Other research is inconclusive in regard to the question whether gender is associated with the amount of caregiver distress (Sharma et al. 2016; Baronet 1999).

Assortive mating (non-random partner choice) might influence the relationship between an HF-ASD patient and spouse. Baron-Cohen (2006) suggested that assortive mating between two high systemizers (people with a high preference to lawfulness, predictability and categorizing information) would lead to more autistic children, but Hoekstra et al. (2007) found no evidence for assortive mating with respect to mutual autistic traits. It is unclear to what extent assortive mating might influence the consequences experienced by a spouse of an HF-ASD patient. One could suggest that spouses who have several autistic traits themselves (broad phenotype) would be less bothered or burdened by the social handicaps of their autistic partners. On the other hand, when someone is feeling overwhelmed by an outside world that they do not completely understand themselves, the strain of caring for someone with the same problems could be experienced as burdensome.

Contrary to the assortive mating theory, HF-ASD subjects might also be attractive to empathic, supporting partners 
who feel an urge to care for them, and compensate for their limitations, or to partners who have been emotionally neglected in their youths and tend to choose a partner who repeats this emotional neglecting. However, receiving no emotional reciprocity in return might drain and strain them in the long run.

Literature is inconsistent on whether ASD symptom severity contributes to levels of consequences (Ricard et al. 1999; Tint and Weiss 2016). Mothers often report higher levels of consequences when children with ASD show more disruptive behavior or higher ASD symptom severity (Ekas and Whitman 2010; Tomeny 2016). Also, Renty and Roeyers (2007) found that spouses of men with ASD reported higher levels of marital satisfaction when their husbands showed less autism-specific traits as measured with the AQ. In our sample, the level of ASD symptoms recognized by the SO was not correlated to the level of consequences they experienced. Reliability of the AQ domains in our sample was comparable to that of Hoekstra et al. (2008).

To our knowledge this is the first time that the caregiver consequences for those involved with an adult with HFASD have been examined using the IEQ. Even though most patients in our clinic had not been diagnosed with ASD during childhood, the impact of their limitations on their surroundings was substantial.

Because of the consequences experienced by spouses of patients with HF-ASD, as found in this study and voiced in the psycho-education group meetings, we believe that extra attention is needed for this group. They experience a lot of interpersonal strain in their relationships and are at risk of developing mental health problems themselves.

\section{Limitations of This Study}

The IEQ has been validated in schizophrenia and depression samples, and has been used with many different psychiatric disorders since, but it has not officially been validated yet with respect to ASD. Cronbach's alpha was acceptable for the overall score and for 3 of the 4 sub-scales but not for the subscale Supervision. Items in this subscale, like "how often during the past 4 weeks have you guarded your relative/friend from committing dangerous acts" or "have you guarded your relative/friend from taking illegal drugs" are possibly not as applicable to HF-ASD as they are to depression or schizophrenia. These were also items that could not be included in one of the factors of the preliminary exploratory factor analysis, which showed a slightly different factor structure compared to the standard IEQ structure. Tension seems to be an issue in ASD, which confirms the results described in this article.

Even though a Confirmatory Factor Analysis was not performed due to the small sample size, it is encouraging to see that the IEQ in ASD seems to have a reasonable amount of reliability and validity. A larger sample size is needed for official validation for the IEQ in ASD. Also, more studies need to be carried out to replicate our findings.

Another limitation concerns the different backgrounds and characteristics of the samples, which reflect the different context in which the caregiving takes place, and also reflects the age and gender difference between the disorders. The ASD data were collected from SO who joined a psycho-educational ASD course in a specialized outpatient clinic. Not all patients diagnosed with ASD participated in this group, and because of the different reasons for not participating we cannot say for sure in which direction a selection bias has influenced our results. However, all data were from SO who were in close contact with a patient, and experienced consequences more or less on a daily basis.

ASD patients were diagnosed between 2006 and 2009, the DSM IV-TR (American Psychiatric Association 1994) version was used for classification. As the DSM-IV subclassifications are no longer applicable in DSM 5 (American Psychiatric Association 2013), we have only reported the frequencies of these sub-classifications and have not included them in further analyses.

Recent studies (Buck et al. 2014; Cawthorpe 2017; De-la-Iglesia and Olivar 2015; Hofvander et al. 2009; Orinstein et al. 2015; Cadman et al. 2012) suggest that co-morbid psychiatric conditions (e.g. depression) make life more difficult especially for adults with HF-ASD. This would probably also be of impact on the SO and of influence on the consequences they experience. Unfortunately, no data concerning co-morbid psychiatric disorders are available for the HF-ASD sample, nor for the depression and schizophrenia sample.

Acknowledgments Part of the data used in this study was published earlier in Psychiatry Research and was used with permission of one of the study authors: Dr. Bob van Wijngaarden, who is second author of this manuscript (van Wijngaarden et al. 2009)

Author Contributions IG participated in the study design and data collection, performed statistical analysis and interpretation of the data and drafted the manuscript. BvW contributed to the data collection, performed statistical analysis and interpretation of the data and helped to draft the manuscript. CK conceived of the study, participated in the design, collection of data and coordination of the study and helped to draft the manuscript. All authors read and approved the final manuscript.

\section{Compliance with Ethical Standards}

Conflict of interest The authors declare that they have no conflict of interest.

Informed Consent Informed consent was obtained from all the individual participants included in the study. 
Open Access This article is distributed under the terms of the Creative Commons Attribution 4.0 International License (http://creativecommons.org/licenses/by/4.0/), which permits unrestricted use, distribution, and reproduction in any medium, provided you give appropriate credit to the original author(s) and the source, provide a link to the Creative Commons license, and indicate if changes were made.

\section{References}

American Psychiatric Association (1994). Diagnostic and statistical manual of mental disorders (IV-TR ed.). Washington DC: American Psychiatric Publishing.

American Psychiatric Association (2013). Diagnostic and statistical manual of mental disorders (5th ed.). Arlington, VA: American Psychiatric Publishing.

Baron-Cohen, S. (1991). The development of a theory of mind in autism: Deviance and delay? Psychiatric Clinics of North America, 14(1), 33-51.

Baron-Cohen, S. (2000). Is asperger syndrome/high-functioning autism necessarily a disability? Development and Psychopathology, 12(3), 489-500.

Baron-Cohen, S. (2006). The hyper-systemizing, assortative mating theory of autism. Progress in Neuro-Psychopharmacology \& Biological Psychiatry, 30(5), 865-872. https://doi. org/10.1016/j.pnpbp.2006.01.010.

Baron-Cohen, S., Hoekstra, R. A., Knickmeyer, R., \& Wheelwright, S. (2006). The Autism-Spectrum Quotient (AQ)—adolescent version. Journal of Autism and Developmental Disorders, 36(3), 343-350. https://doi.org/10.1007/s10803-006-0073-6.

Baron-Cohen, S., Wheelwright, S., Skinner, R., Martin, J., \& Clubley, E. (2001). The autism-spectrum quotient (AQ): Evidence from Asperger syndrome/high-functioning autism, males and females, scientists and mathematicians. Journal of Autism and Developmental Disorders, 31(1), 5-17.

Baronet, A. M. (1999). Factors associated with caregiver burden in mental illness: A critical review of the research literature. Clinical Psychology Review, 19(7), 819-841.

Barusch, A. S., \& Spaid, W. M. (1989). Gender differences in caregiving: Why do wives report greater burden? Gerontologist, 29(5), 667-676.

Becker, T., Knapp, M., Knudsen, H. C., Schene, A., Tansella, M., Thornicroft, G., et al. (1999). The EPSILON study of schizophrenia in five European countries: Design and methodology for standardizing outcome measures and comparing patterns of care and service costs. The British Journal of Psychiatry, 175, 514-521. https://doi.org/10.1192/bjp.175.6.514.

Becker, T., Knapp, M., Knudsen, H. C., Schene, A., Tansella, M., Thornicroft, G., et al. (2000). Reliable outcome measure for mental health service research in five European countries: The EPSILON Study. Aims, outcome measure, study sites and patient sample. The British Journal of Psychiatry, 177, s1-s7. https://doi.org/10.1192/bjp.177.39.s1.

Buck, T. R., Viskochil, J., Farley, M., Coon, H., McMahon, W. M., Morgan, J., et al. (2014). Psychiatric comorbidity and medication use in adults with autism spectrum disorder. Journal of Autism and Developmental Disorders, 44(12), 3063-3071. https://doi.org/10.1007/s10803-014-2170-2.

Burke, M., \& Heller, T. (2016). Individual, parent and social-environmental correlates of caregiving experiences among parents of adults with autism spectrum disorder. Journal of Intellectual Disability Research, 60(5), 401-411. https://doi.org/10.1111/ jir.12271.

Cadman, T., Eklund, H., Howley, D., Hayward, H., Clarke, H., Findon, J., et al. (2012). Caregiver burden as people with autism spectrum disorder and attention-deficit/hyperactivity disorder transition into adolescence and adulthood in the United Kingdom. Journal of the American Academy of Child and Adolescent Psychiatry, 51(9), 879-888. https://doi.org/10.1016/j. jaac.2012.06.017.

Cawthorpe, D. (2017). Comprehensive description of comorbidity for autism spectrum disorder in a general population. Permanente Journal. https://doi.org/10.7812/tpp/16-088.

Cuijpers, P., \& Stam, H. (2000). Burnout among relatives of psychiatric patients attending psychoeducational support groups. Psychiatric Services (Washington, D.C.), 51(3), 375-379. https://doi. org/10.1176/appi.ps.51.3.375.

De-la-Iglesia, M., \& Olivar, J. S. (2015). Risk factors for depression in children and adolescents with high functioning autism spectrum disorders. The Scientific World Journal, 2015, 127853, https://doi. org/10.1155/2015/127853.

Ekas, N. V., \& Whitman, T. L. (2010). Autism symptom topography and maternal socioemotional functioning. American Journal on Intellectual and Developmental Disabilities, 115(3), 234-249. https://doi.org/10.1352/1944-7558-115.3.234.

Ekas, N. V., Whitman, T. L., \& Shivers, C. (2009). Religiosity, spirituality, and socioemotional functioning in mothers of children with autism spectrum disorder. Journal of Autism and Developmental Disorders, 39(5), 706-719. https://doi.org/10.1007/ s10803-008-0673-4.

Field, A. (2013). Discovering statistics using IBM SPSS statistics (4th ed.). London: Sage.

Gelkopf, M., \& Roe, D. (2014). Evaluating outcome domains assessing caregivers of individuals with mental illness: A review. Family Process, 53(1), 150-174. https://doi.org/10.1111/famp.12056.

Geurtsen, G. J., Meijer, R., van Heugten, C. M., Martina, J. D., \& Geurts, A. C. (2010). Experienced emotional burden in caregivers: Psychometric properties of the Involvement Evaluation Questionnaire in caregivers of brain injured patients. Clinical Rehabilitation, 24(10), 935-943. https://doi. org/10.1177/0269215510367990.

Goldberg, D. P., Gater, R., Sartorius, N., Ustun, T. B., Piccinelli, M., Gureje, O., et al. (1997). The validity of two versions of the GHQ in the WHO study of mental illness in general health care. Psychological Medicine, 27(1), 191-197.

Goldberg, D. P., Oldehinkel, T., \& Ormel, J. (1998). Why GHQ threshold varies from one place to another. Psychological Medicine, 28(4), 915-921.

Goldberg, D. P., \& Williams, P. (1988). The user's guide to the General Health Questionnaire. Windsor: NFER-Nelson.

Goncalves-Pereira, M., Xavier, M., van Wijngaarden, B., Papoila, A. L., Schene, A. H., \& Caldas-de-Almeida, J. M. (2013). Impact of psychosis on Portuguese caregivers: A cross-cultural exploration of burden, distress, positive aspects and clinical-functional correlates. Social Psychiatry and Psychiatric Epidemiology, 48(2), 325-335. https://doi.org/10.1007/s00127-012-0516-7.

Goossens, P. J., van Wijngaarden, B., Knoppert-van der Klein, E. A., \& van Achterberg, T. (2008). Family caregiving in bipolar disorder: Caregiver consequences, caregiver coping styles, and caregiver distress. International Journal of Social Psychiatry, 54(4), 303316. https://doi.org/10.1177/0020764008090284.

Granek, L., Danan, D., Bersudsky, Y., \& Osher, Y. (2016). Living with bipolar disorder: The impact on patients, spouses, and their marital relationship. Bipolar Disorders, 18(2), 192-199. https://doi. org/10.1111/bdi.12370.

Hartley, S. L., Barker, E. T., Seltzer, M. M., Greenberg, J. S., \& Floyd, F. J. (2011). Marital satisfaction and parenting experiences of mothers and fathers of adolescents and adults with autism. American Journal on Intellectual and Developmental Disabilities, 116(1), 81-95. https://doi.org/10.1352/1944-7558-116.1.81. 
Hartley, S. L., \& Schultz, H. M. (2015). Support needs of fathers and mothers of children and adolescents with autism spectrum disorder. Journal of Autism and Developmental Disorders, 45(6), 1636-1648. https://doi.org/10.1007/s10803-014-2318-0.

Hayes, S. A., \& Watson, S. L. (2013). The impact of parenting stress: A meta-analysis of studies comparing the experience of parenting stress in parents of children with and without autism spectrum disorder. Journal of Autism and Developmental Disorders, 43(3), 629-642. https://doi.org/10.1007/s10803-012-1604-y.

Hoekstra, R. A., Bartels, M., Cath, D. C., \& Boomsma, D. I. (2008). Factor structure, reliability and criterion validity of the AutismSpectrum Quotient (AQ): A study in Dutch population and patient groups. Journal of Autism and Developmental Disorders, 38(8), 1555-1566. https://doi.org/10.1007/s10803-008-0538-x.

Hoekstra, R. A., Bartels, M., Verweij, C. J., \& Boomsma, D. I. (2007). Heritability of autistic traits in the general population. Archives of Pediatrics \& Adolescent Medicine, 161(4), 372-377. https://doi. org/10.1001/archpedi.161.4.372.

Hofvander, B., Delorme, R., Chaste, P., Nyden, A., Wentz, E., Stahlberg, O., et al. (2009). Psychiatric and psychosocial problems in adults with normal-intelligence autism spectrum disorders. BMC Psychiatry, 9, 35. https://doi.org/10.1186/1471-244x-9-35.

Karst, J. S., \& Van Hecke, A. V. (2012). Parent and family impact of autism spectrum disorders: A review and proposed model for intervention evaluation. Clinical Child and Family Psychology Review, 15(3), 247-277. https://doi.org/10.1007/ s10567-012-0119-6.

Kronenberg, L. M., Goossens, P. J., van Busschbach, J. T., van Achterberg, T., \& van den Brink, W. (2016). Burden and expressed emotion of caregivers in cases of adult substance use disorder with and without attention deficit/hyperactivity disorder or autism spectrum disorder. International Journal of Mental Health and Addiction, 14, 49-63. https://doi.org/10.1007/s11469-015-9567-9.

Kumar, C. N., Suresha, K. K., Thirthalli, J., Arunachala, U., \& Gangadhar, B. N. (2015). Caregiver burden is associated with disability in schizophrenia: Results of a study from a rural setting of south India. International Journal of Social Psychiatry, 61(2), 157-163. https://doi.org/10.1177/0020764014537637.

Lau, W., \& Peterson, C. C. (2011). Adults and children with Asperger syndrome: Exploring adult attachment style, marital satisfaction and satisfaction with parenthood. Research in Autism Spectrum Disorders, 5(1), 392-399. https://doi.org/10.1016/j. rasd.2010.06.001.

Lecavalier, L., Leone, S., \& Wiltz, J. (2006). The impact of behaviour problems on caregiver stress in young people with autism spectrum disorders. Journal of Intellectual Disability Research, $50(\mathrm{Pt}$ 3), 172-183. https://doi.org/10.1111/j.1365-2788.2005.00732.x.

Lehnhardt, F. G., Gawronski, A., Pfeiffer, K., Kockler, H., Schilbach, L., \& Vogeley, K. (2013). The investigation and differential diagnosis of Asperger syndrome in adults. Deutsches Arzteblatt International, 110(45), 755-763. https://doi.org/10.3238/ arztebl.2013.0755.

Lin, L. Y. (2011). Factors associated with caregiving burden and maternal pessimism in mothers of adolescents with an autism spectrum disorder in Taiwan. Occupational therapy International, 18(2), 96-105. https://doi.org/10.1002/oti.305.

Loomes, R., Hull, L., \& Mandy, W. P. L. (2017). What is the maleto-female ratio in autism spectrum disorder? a systematic review and meta-analysis. Journal of the American Academy of Child and Adolescent Psychiatry, 56(6), 466-474. https://doi.org/10.1016/j. jaac.2017.03.013.

Lounds, J., Seltzer, M. M., Greenberg, J. S., \& Shattuck, P. T. (2007). Transition and change in adolescents and young adults with autism: Longitudinal effects on maternal well-being. American Journal of Mental Retardation, 112(6), 401-417. https://doi. org/10.1352/0895-8017(2007)112[401:taciaa]2.0.co;2.
Magne-Ingvar, U., \& Ojehagen, A. (2005). Significant others of persons with mental health problems: The testing of a questionnaire on the burden of significant others. Nordic Journal of Psychiatry, 59(6), 441-447. https://doi.org/10.1080/08039480500364841.

Marriage, S., Wolverton, A., \& Marriage, K. (2009). Autism spectrum disorder grown up: A chart review of adult functioning. Journal of the Canadian Academy of Child and Adolescent Psychiatry $=$ Journal de L'Academie Canadienne de Psychiatrie de L'Enfant et de L'Adolescent, 18(4), 322-328.

Martin, J., Padierna, A., van Wijngaarden, B., Aguirre, U., Anton, A., Munoz, P., et al. (2015). Caregivers consequences of care among patients with eating disorders, depression or schizophrenia. BMC Psychiatry, 15, 124. https://doi.org/10.1186/s12888-015-0507-9.

Milgram, N. A., \& Atzil, M. (1988). Parenting stress in raising autistic children. Journal of Autism and Developmental Disorders, 18(3), 415-424.

Muhle, R., Trentacoste, S. V., \& Rapin, I. (2004). The genetics of autism. Pediatrics, 113(5), e472-e486.

Murphy, N. A., Christian, B., Caplin, D. A., \& Young, P. C. (2007). The health of caregivers for children with disabilities: Caregiver perspectives. Child, 33(2), 180-187. https://doi. org/10.1111/j.1365-2214.2006.00644.x.

Orinstein, A., Tyson, K. E., Suh, J., Troyb, E., Helt, M., Rosenthal, M., et al. (2015). Psychiatric symptoms in youth with a history of autism and optimal outcome. Journal of Autism and Developmental Disorders, 45(11), 3703-3714. https://doi.org/10.1007/ s10803-015-2520-8.

Orsmond, G. I., Lin, L. Y., \& Seltzer, M. M. (2007). Mothers of adolescents and adults with autism: Parenting multiple children with disabilities. Intellectual and Developmental Disabilities, 45(4), 257-270. https://doi.org/10.1352/1934-9556(2007)45[257:moa aaw]2.0.co;2.

Ostman, M., Wallsten, T., \& Kjellin, L. (2005). Family burden and relatives' participation in psychiatric care: Are the patient's diagnosis and the relation to the patient of importance? International Journal of Social Psychiatry, 51(4), 291-301. https://doi. org/10.1177/0020764005057395.

Rao, P. A., \& Beidel, D. C. (2009). The impact of children with highfunctioning autism on parental stress, sibling adjustment, and family functioning. Behavior Modification, 33(4), 437-451. https:// doi.org/10.1177/0145445509336427.

Renty, J., \& Roeyers, H. (2007). Individual and marital adaptation in men with autism spectrum disorder and their spouses: The role of social support and coping strategies. Journal of Autism and Developmental Disorders, 37(7), 1247-1255. https://doi.org/10.1007/ s10803-006-0268-x.

Ricard, N., Bonin, J. P., \& Ezer, H. (1999). Factors associated with burden in primary caregivers of mentally ill patients. International Journal of Nursing Studies, 36(1), 73-83.

Schalock, R. L., Luckasson, R. A., \& Shogren, K. A. (2007). The renaming of mental retardation: Understanding the change to the term intellectual disability. Intellectual and Developmental Disabilities, 45(2), 116-124. https://doi. org/10.1352/1934-9556(2007)45[116:tromru]2.0.co;2.

Schene, A. H. (1990). Objective and subjective dimensions of family burden toward an integrative framework for research. Social Psychiatry and Psychiatric Epidemiology, 25, 289-297. https://doi. org/10.1007/bf00782883.

Schmitz, N., Kruse, J., \& Tress, W. (1999). Psychometric properties of the General Health Questionnaire (GHQ-12) in a German primary care sample. Acta Psychiatrica Scandinavica, 100(6), 462-468.

Sharma, N., Chakrabarti, S., \& Grover, S. (2016). Gender differences in caregiving among family-caregivers of people with mental illnesses. World Journal Psychiatry, 6(1), 7-17. https://doi. org/10.5498/wjp.v6.i1.7. 
Smith, L. E., Greenberg, J. S., \& Mailick, M. R. (2012). Adults with autism: Outcomes, family effects, and the multi-family group psychoeducation model. Current Psychiatry Reports, 14(6), 732-738. https://doi.org/10.1007/s11920-012-0328-1.

Tint, A., \& Weiss, J. A. (2016). Family wellbeing of individuals with autism spectrum disorder: A scoping review. Autism, 20(3), 262275. https://doi.org/10.1177/1362361315580442.

Tomeny, T. S. (2016). Parenting stress as an indirect pathway to mental health concerns among mothers of children with autism spectrum disorder. Autism. https://doi.org/10.1177/1362361316655322.

van Steijn, D. J., Oerlemans, A., Van Aken, M. A., Buitelaar, J., \& Rommelse, N. (2014). The reciprocal relationship of ASD, ADHD, depressive symptoms and stress in parents of children with ASD and/or ADHD. Journal of Autism and Developmental Disorders, 44(5), 1064-1076.

van Steijn, D. J., Richards, J. S., Oerlemans, A., de Ruiter, S. W., Van Aken, M. A., Franke, B., et al. (2012). The co-occurrence of autism spectrum disorder and attention-deficit/hyperactivity disorder symptoms in parents of children with ASD or ASD with ADHD. Journal of Child Psychology and Psychiatry, 53(9), 954-963.

van Tongerloo, M. A., van Wijngaarden, P. J., van der Gaag, R. J., \& Lagro-Janssen, A. L. (2015). Raising a child with an Autism Spectrum Disorder: 'If this were a partner relationship, I would have quit ages ago'. Family Practice, 32(1), 88-93. https://doi. org/10.1093/fampra/cmu076. van Wijngaarden, B., Koeter, M., Knapp, M., Tansella, M., Thornicroft, G., Vazquez-Barquero, J. L., et al. (2009). Caring for people with depression or with schizophrenia: Are the consequences different? Psychiatry Research, 169(1), 62-69. https://doi.org/10.1016/j. psychres.2008.06.013.

van Wijngaarden, B., Schene, A. H., Koeter, M., Vazquez-Barquero, J. L., Knudsen, H. C., Lasalvia, A., et al. (2000). Caregiving in schizophrenia: Development, internal consistency and reliability of the Involvement Evaluation Questionnaire-European Version. EPSILON Study 4. European Psychiatric Services: Inputs linked to outcome domains and needs. British Journal of Psychiatry, 177(Suppl 39), s21-27.

van Wijngaarden, B., Schene, A. H., \& Koeter, M. W. J. (2004). Family caregiving in depression: Impact on caregivers' daily life, distress, and help seeking. Journal of Affective Disorders, 81, 211-222. https://doi.org/10.1016/s0165-0327(03)00168-x.

Weiss, J. A., Tint, A., Paquette-Smith, M., \& Lunsky, Y. (2016). Perceived self-efficacy in parents of adolescents and adults with autism spectrum disorder. Autism, 20(4), 425-434. https://doi. org/10.1177/1362361315586292.

Wittmund, B., Wilms, H. U., Mory, C., \& Angermeyer, M. C. (2002). Depressive disorders in spouses of mentally ill patients. Social Psychiatry and Psychiatric Epidemiology, 37(4), 177-182. 